\title{
The implementation of EPP software using HIV prevalence data from studies conducted in Greece
}

\author{
Georgios Nikolopoulos*, Chryssa Tsiara, Chryssoula Botsi \\ From $16^{\text {th }}$ International Symposium on HIV and Emerging Infectious Diseases \\ Marseille, France. 24-26 March 2010
}

\section{Background}

In Greece, HIV/AIDS surveillance is based mainly on the case reporting system, which, however, is affected by patterns of testing and reporting. Specific information on the prevalence and incidence of HIV disease is required for an effective and well-planned response to the epidemic. The Estimation and Projection Package (EPP) is a software developed by UNAIDS and partners, which assists countries to map their HIV epidemic on the basis of available HIV prevalence data. The aims of the present study include: i) the systematic review of Greek and international literature in order to retrieve relevant HIV prevalence studies carried out in Greece, and ii) the use of the extracted prevalence estimates in EPP to produce the Greek epidemic curve.

\section{Methods}

HIV prevalence data were extracted from studies conducted in Greece among high risk behavior groups [Injecting Drug Users (IDUs) and Men who have Sex with Men (MSM)] and the general population. The EPP software was employed to generate an epidemic curve.

\section{Results}

According to EPP data, since the beginning of the epidemic the HIV prevalence was steadily increasing and reached $0.13 \%$ in 2009 . Concerning IDUs, a secular decrease was observed and the current prevalence estimate approximates $0.4 \%$. After a sharp increase during the $90 \mathrm{~s}$, the HIV prevalence among MSM has been stabilized to the considerably high number of $6.5 \%$.

\footnotetext{
* Correspondence: nikolopoulos@keelpno.gr

hellenic Centre For Diseases Control And Prevention, Amarousio, Greece
}

\section{Discussion}

EPP software incorporating data from HIV prevalence studies, indicated that HIV/AIDS epidemic in Greece is concentrated on MSM, with an estimated prevalence above the $5 \%$ threshold used by WHO for concentrated epidemics. The results are consistent with estimates derived from the National HIV/AIDS reporting system and highlight the need for intensified interventions in the sub-population of MSM.

Published: 11 May 2010

doi:10.1186/1742-4690-7-S1-P129

Cite this article as: Nikolopoulos et al:: The implementation of EPP software using HIV prevalence data from studies conducted in Greece. Retrovirology 2010 7(Suppl 1):P129.

\section{Submit your next manuscript to BioMed Central and take full advantage of: \\ - Convenient online submission \\ - Thorough peer review \\ - No space constraints or color figure charges \\ - Immediate publication on acceptance \\ - Inclusion in PubMed, CAS, Scopus and Google Scholar \\ - Research which is freely available for redistribution \\ Submit your manuscript at www.biomedcentral.com/submit}

